\title{
Biocomposite Films Based on $\kappa-$ Carrageenan/Locust Bean Gum Blends and Clays: Physical and Antimicrobial Properties
}

\author{
Joana T. Martins • Ana I. Bourbon • Ana C. Pinheiro • \\ Bartolomeu W. S. Souza • Miguel A. Cerqueira • \\ António A. Vicente
}

Received: 11 January 2012 / Accepted: 2 April 2012 /Published online: 29 April 2012

(C) Springer Science+Business Media, LLC 2012

\begin{abstract}
The aims of this work were to evaluate the physical and antimicrobial properties of biodegradable films composed of mixtures of $\mathrm{K}$-carrageenan ( $\mathrm{K}$-car) and locust bean gum (LBG) when organically modified clay Cloisite 30B (C30B) was dispersed in the biopolymer matrix. Filmforming solutions were prepared by adding $\mathrm{C} 30 \mathrm{~B}$ (ranging from 0 to $16 \mathrm{wt} . \%$ ) into the $\mathrm{K}$-car/LBG solution (40/60 wt.\%) with $0.3 \%(w / v)$ of glycerol. Barrier properties (water vapour permeability, $P_{\text {vapour }} ; \mathrm{CO}_{2}$ and $\mathrm{O}_{2}$ permeabilities), mechanical properties (tensile strength, TS, and elongation-at-break, EB) and thermal stability of the resulting films were determined and related with the incorporation of C30B. Also, X-ray diffraction (XRD) was done in order to investigate the effect of C30B in film structure. Antimicrobial effects of these films against Listeria monocytogenes, Escherichia coli and Salmonella enterica were also evaluated. The increase of clay concentration causes a decrease of $P_{\text {vapour }}$ (from $5.34 \times 10^{-11}$ to $3.19 \times 10^{-11} \mathrm{~g}\left(\mathrm{~m} \mathrm{sPa}^{-1}\right)$ and an increase of the $\mathrm{CO}_{2}$ permeability (from $2.26 \times 10^{-14}$ to $\left.2.91 \times 10^{-14} \mathrm{~g} \mathrm{(m} \mathrm{sPa}\right)^{-1}$ ) and did not changed significantly the $\mathrm{O}_{2}$ permeability for films with 0 and 16 wt.\% C30B, respectively. Films with 16 wt.\% clay exhibited the highest values of TS (33.82 MPa) and EB $(29.82 \%)$. XRD patterns of the films indicated that a degree
\end{abstract}

J. T. Martins · A. I. Bourbon - A. C. Pinheiro • B. W. S. Souza •

M. A. Cerqueira $\cdot$ A. A. Vicente $(\square)$

Institute for Biotechnology and Bioengineering (IBB),

Centre of Biological Engineering, University of Minho,

Campus de Gualtar,

4710-057 Braga, Portugal

e-mail: avicente@deb.uminho.pt

B. W. S. Souza

Departamento de Engenharia de Pesca,

Universidade Federal do Ceará,

Campus do Pici,

Fortaleza, Ceará, Brazil of exfoliation is attained depending on clay concentration. $\mathrm{K}$ car/LBG-C30B films exhibited an inhibitory effect only against $L$. monocytogenes. $\mathrm{k}$-car/LBG-C30B composite films are a promising alternative to synthetic films in order to improve the shelf life and safety of food products.

Keywords Biocomposite films · Polysaccharide · Galactomannan $\cdot$ Clays $\cdot$ Physical properties

\section{Introduction}

New bio-based materials have been exploited to develop edible and biodegradable films as an effort to extend shelflife and improve the quality of food while reducing synthetic packaging waste. Biopolymer films offer a variety of advantages compared to synthetic films, e.g. biodegradability, use of renewable sources and potential edibility. Due to the deliberate interactions with the food or the food environment, edible coatings and films are excellent alternatives to traditional food packaging. However, these biopolymer materials could present poor mechanical properties and remain water sensitive and, therefore, lose their water vapour barrier properties (Sorrentino et al. 2007).

In this context, improvements in the physical properties of these films have been made by reinforcement of the polymer matrix with layered clay minerals such as montmorillonite (MMT) (Park et al. 2003; Sorrentino et al. 2007). The application of clays to biodegradable films may open new possibilities to improve biopolymer properties for food packaging applications. A number of researchers have presented work in the field of biopolymer-based composite films, where films are filled with fillers such as layer silicates, carbon nanotubes, cellulose and nanocrystals (Ruiz-Hitzky et al. 
2008; Lee and Kim 2010). Clays are naturally occurring materials composed primarily of fine-grained minerals. MMT is among the most commonly used layered silicates and is a promising material with high aspect ratio and surface area (Sorrentino et al. 2007). MMT consists of stacks of negatively charged silicate layers, with positive counter-ions in the interlamellar space or gallery (Ruiz-Hitzky et al. 2010). The silicate layers could be organically modified to increase their hydrophobicity, being the exchange of hydrated cations with organic modifiers such as alkylammonium cations the most popular method used for clay modification. The modified organic clay is known as organoclay (Ruiz-Hitzky et al. 2010). Research on biocomposite films has been a focus in recent years. Chitosan (Casariego et al. 2009), pectin (Vartiainen et al. 2010) and gelatin (Voon et al. 2010) are examples of biopolymer-based films in which clays were incorporated. Moreover, the addition of clays has been related to improvements in the overall performance of biopolymers, enhancing their mechanical, thermal and barrier properties, usually even at very low concentrations (Ray and Bousmina 2005). Thus, clays have an important role to improve the feasibility of use of biopolymers in food packaging.

Antimicrobial character is a particularly desirable property when clay is impregnated in the film. Sothornvit et al. (2010) reported that whey protein isolate/clay composite films comprised a bacteriostatic effect against Listeria monocytogenes. This characteristic can be used to enhance the shelf-life of a variety of foods such as processed meats, cheese, confectionery and cereals.

The blending of polysaccharides such as LBG and K-car could provide a synergistic effect (Arda et al. 2009) affecting their physicochemical properties. Such effects turn K-car/LBG system as edible films and coatings very attractive (Martins et al. 2011). However, little attention has been paid on the properties related to these biopolymers used as food packaging. Even though the development and characterization of polysaccharide blends films with clays has been reported, such as K/L-hybrid carrageenan blends with clays (SanchezGarcia et al. 2010) and K-car/pectin blends and mica flakes (Alves et al. 2010), the interactive effect of clay on the properties of $\mathrm{K}$-car/LBG-based composite films for food packaging needs to be studied. Therefore, this study was aimed at evaluating the improvements of the films' microbiological and physical properties (e.g. barrier, mechanical and thermal properties) in the presence of clay added to $\mathrm{K}$-car/LBG films.

\section{Materials and Methods}

Materials

K-Car (Gelcarin DX5253) and LBG (Genu gum type RL200) were purchased from FMC Biopolymer (Norway) and
CP Kelco (USA), respectively. Glycerol $87 \%$ was obtained from Panreac (Spain). Montmorillonite organoclay modified by the addition of quaternary ammonium salts - Cloisite $^{\circledR}$ 30B - was supplied by Southern Clay Products, Inc. (TX, USA). Cloisite 30B (C30B) has one bulky group of tallow and two short ethyl alcohol groups. C30B is commercially available as a powder ( 2 to $13 \mu \mathrm{m})$ and contains methyl tallow bis-2-hydroxyethyl ammonium chloride. As reported by the manufacturer, $\mathrm{C} 30 \mathrm{~B}$ has a cation exchange capacity of $90 \mathrm{meq} / 100 \mathrm{~g}$ clay and it has been approved by FDA for use as a food contacting material (Sothornvit et al. 2010).

\section{Preparation of k-Car/LBG Composite Films}

Polysaccharide dispersions were prepared using the method described by Martins et al. (2011). To prepare K-car/LBG films without clay, 40 and $60 \%$ ( $w / w$, dry basis) of $\mathrm{K}$-car and LBG, respectively, was suspended in distilled water under agitation during $1 \mathrm{~h}$ at $25{ }^{\circ} \mathrm{C}$. The film solutions were homogenized at $80{ }^{\circ} \mathrm{C}$ and stirred during $30 \mathrm{~min}$ in the presence of $30 \%$ ( $w / w$, dry basis) glycerol (plasticizer) until a homogeneous solution was obtained.

To prepare $\mathrm{K}$-car/LBG composite films, C30B were used at five different levels $-1,2,4,8$ and $16 \%$ ( $w / w$, dry basis). The method used was based on methods described by Sothornvit et al. (2010) and Lim et al. (2010) with some modifications. The powder was dispersed into distilled water under magnetic stirring for $24 \mathrm{~h}$ for hydration. Each polysaccharide powder was then dissolved into the clay solution after the addition of glycerol (30\% w/w, dry basis). This suspension was sonicated for $30 \mathrm{~min}$ using an ultrasonic water bath (Sonicor Instrument Corp., SC-52) and then was heated for $30 \mathrm{~min}$ at $70{ }^{\circ} \mathrm{C}$ in a water bath.

Film-forming solutions with and without clays were then degassed under vacuum to remove dissolved air bubbles. Then, $28 \mathrm{~mL}$ of solution was cast into polystyrene Petri dishes and dried at $35{ }^{\circ} \mathrm{C}$ during $16 \mathrm{~h}$. The casting is done with the filmforming solution at $60^{\circ} \mathrm{C}$ to avoid the solution from turning into a gel at lower temperatures. Films were conditioned in desiccators containing a saturated solution of $\mathrm{Mg}\left(\mathrm{NO}_{3}\right)_{2} \cdot 6 \mathrm{H}_{2} \mathrm{O}$ at $54 \pm 1 \%$ relative humidity (RH) and $20 \pm 1{ }^{\circ} \mathrm{C}$ until further use.

\section{Film Thickness}

Films thickness was measured at ten different points using a digital micrometer (no. 293-561, Mitutoyo, Japan) with $\pm 0.001-\mathrm{mm}$ accuracy. The mean values were used to calculate permeability and mechanical values.

\section{X-Ray Diffraction Analysis}

X-ray diffraction (XRD) analysis patterns of pure clay in powder form and $\mathrm{K}$-car/LBG films with or without clay were 
obtained using a Bruker D8 Discover (USA) X-ray diffractometer $(40 \mathrm{kV}, 40 \mathrm{~mA})$ equipped with $\mathrm{Cu}$ radiation at a wavelength of $0.154 \mathrm{~nm}(1.5406 \AA$ ). All experiments were carried out with a scanning rate of $0.04 \% \mathrm{~min}$ from 1 to $40^{\circ}$ ( $2 \theta$ range). The interlayer spacing of the films containing the modified clays was determined by the XRD peak, using Bragg's equation $(\lambda=2 d \sin \theta)$, where $\lambda$ corresponds to the wavelength of the X-ray radiation (1.5405 $\AA$ ), $d$ corresponds to the interlayer spacing between the diffraction lattice planes, and $\theta$ is the measured diffraction angle of the peak in the XRD pattern. The measurements were done in triplicate.

\section{Fourier Transform Infrared Spectroscopy}

Fourier transform infrared spectroscopy (FTIR) spectra of the films were recorded with a Perkin-Elmer 16 PC (Boston, MA, USA) FTIR spectrometer in the wavelength range 4,000$400 \mathrm{~cm}^{-1}$ at a resolution of $4 \mathrm{~cm}^{-1}$ using attenuated total reflection mode. FTIR spectroscopy was used to obtain information about the interactions between clay and $\mathrm{K}$-car/LBG in films. The absorbance of each FTIR spectrum was normalized between 0 and 1 . The measurements were done in triplicate.

\section{Films Morphology—Scanning Electron Microscopy}

The K-car/LBG-based composite films were mounted on scanning electron microscopy (SEM) stubs with doublesided adhesive tape. Then, film samples were coated with a thin layer of gold. A Nova NanoSEM 200 (Netherlands) instrument was used to observe the morphologies of the film cross-sections and surface at an accelerating voltage from 10 to $15 \mathrm{kV}$.

\section{Permeability to Gases (Water Vapour, Oxygen and Carbon} Dioxide)

The methodology to measure water vapour permeability $\left(P_{\text {vapour }}\right)$ was described in Casariego et al. (2009). Film samples were sealed on cups containing distilled water, and afterwards they were placed inside a desiccator containing silica gel $\left(0 \% \mathrm{RH} ; 20^{\circ} \mathrm{C}\right)$. To maintain uniform conditions in all samples, a fan was used inside the desiccator. Periodical cup weightings ( $2 \mathrm{~h}$ ) were performed to monitor weight loss over time until a steady state was reached. Finally, water vapour transmission rate (WVTR) was calculated by dividing the slope of the linear regression of weight loss by film area, and $P_{\text {vapour }}\left(\mathrm{g} \mathrm{m}^{-1} \mathrm{~s}^{-1} \mathrm{~Pa}^{-1}\right)$ was calculated as follows:

$P_{\text {vapour }}=($ WVTR $\times L) / \Delta p$

where $L$ is film thickness (m) and $\Delta p$ is water vapour partial pressure difference $(\mathrm{Pa})$ across the two sides of the film. For each measurement, at least three repetitions were made for each type of film.

Oxygen permeability $\left(\mathrm{PO}_{2}\right)$ and carbon dioxide permeability $\left(\mathrm{PCO}_{2}\right)$ measurements were conducted based on Cerqueira et al. (2011). Briefly, the tests were conducted in a gas permeation cell consisting of two chambers and the test film was sandwiched between the two chambers. Measurements were conducted at $20{ }^{\circ} \mathrm{C}$. The permeation gas (oxygen or dioxide carbon) flowed continuously through the lower chamber, and nitrogen (as a sweep gas) was passed through the upper chamber. When the steady state was reached, the penetrated gas $\mathrm{O}_{2}$ or $\mathrm{CO}_{2}$ in the sweep gas stream was analysed by gas chromatography (Chrompack 9001, Middelburg, Netherlands) at $110^{\circ} \mathrm{C}$ with a column Porapak Q 80/100 mesh $2 \mathrm{~m} \times 1 / 8$ in. $\times 2 \mathrm{~mm}$ SS equipped with a hydrogen flame ion detector. Helium was used as carrier gas at $23 \mathrm{~mL} \mathrm{~min}^{-1}$. A standard mixture containing $10 \% \mathrm{CO}_{2}, 20 \% \mathrm{O}_{2}$ and $70 \% \mathrm{~N}_{2}$ was used for calibration. Three replicates for $\mathrm{PO}_{2}$ and $\mathrm{PCO}_{2}$ measurements were obtained for each film sample.

\section{Mechanical Properties}

The mechanical properties of the films were measured with an Instron Universal Testing Machine (Model 4500, Instron Corporation) in accordance to Casariego et al. (2009). Samples $\left(50 \times 20 \mathrm{~mm}^{2}\right)$ were clamped between grips with an initial distance of $30 \mathrm{~mm}$. The force and deformation were recorded during extension at $5 \mathrm{~mm} \mathrm{~min}{ }^{-1}$. The tensile strength (TS) and the elongation-at-break (EB) were determined from nine replicates for each film formulation. TS and EB were expressed in MPa and percentage, respectively. The measurements were done in triplicate.

Thermogravimetric Analysis

Thermogravimetric analysis (TGA) of the film samples was performed between 25 and $580{ }^{\circ} \mathrm{C}$ at a heating rate of $10^{\circ} \mathrm{C}$ min $^{-1}$ using a Shimadzu TGA-50 (Shimadzu Corporation, Kyoto, Japan) analyser. Nitrogen was used as the purge gas. An empty pan was used as a reference. Measurements were done in triplicate.

Evaluation of Antimicrobial Activity In Vitro

\section{Microorganisms Preparation}

Three representative food-pathogenic bacteria were used for testing the antimicrobial activity: Escherichia coli K12, Salmonella enterica (NCTC 12416) and L. monocytogenes (CECT 4031T). The Gram-negative bacteria (E. coli and $S$. enterica) were cultured into TSB (Cultimed, Panreac, Spain) and incubated at $30{ }^{\circ} \mathrm{C}$. The Gram-positive bacterium $(L$. 
monocytogenes) was cultured into BHI broth (Liofilchem, Italy) and incubated at $35{ }^{\circ} \mathrm{C}$. The three bacterial strains were grown for $18 \mathrm{~h}$ prior to any antimicrobial test. To confirm the initial bacterial counts, serially diluted bacterial cultures were plated on the appropriate agar plates: TSA (Cultimed, Panreac) for Gram-negative bacteria and BHI agar (Liofilchem, Italy) for Gram-positive bacteria. The plates were incubated for $24 \mathrm{~h}$ at $37^{\circ} \mathrm{C}$ and the number of viable colonies was counted.

\section{Disc Diffusion Method}

The inhibition zones - qualitative measurement of antimicrobial activity — were measured by using agar disc diffusion assay according to Pranoto et al. (2005) with some modifications. The $\mathrm{K}$-car/LBG films with different concentrations of C30B were cut into 8-mm-diameter discs and then placed on Mueller-Hinton agar plates (Merck, Darmstadt, Germany). These had been previously seeded with $0.1 \mathrm{~mL}$ of inocula containing approximately $10^{5} \mathrm{CFU} / \mathrm{mL}$ of tested bacteria using a sterile cotton swab. The plates were then incubated at $37{ }^{\circ} \mathrm{C}$ for $24 \mathrm{~h}$. The diameter of the inhibitory zone surrounding film discs and the film contact area with agar surface were measured in millimeters with a calliper. All experiments were done in triplicate.

\section{Bacterial Count Method}

In order to ascertain in more detail the inhibition already observed by the disc diffusion assay, quantitative antimicrobial activity of the films was determined for the aforementioned microorganisms that tested positive for antimicrobial effect. The methodology followed for the determination of antimicrobial effectiveness of films was the viable cell count method adapted from Rhim et al. (2009). To ensure that the antimicrobial studies reflect solely the effect of the clays present in the films' formulation, the following samples were prepared in separate test flasks: no film (control), film without clay ( 0 wt.\% C30B) and film containing 1, 2, 4, 8 or 16 wt.\% C30B. Antimicrobial activity was determined by placing film discs (20 $\mathrm{mm}$ in diameter) containing different concentrations of clay on individual test flasks. Bacterial strains were grown overnight and diluted with fresh medium to achieve an approximate density of $1 \times 10^{7} \mathrm{CFU} / \mathrm{mL}$ in each test flask. Then, $50 \mathrm{~mL}$ of the inoculum was aseptically added to each of the flasks containing the sample films. The microorganism tested (L. monocytogenes) was present in each of the test flasks. L. monocytogenes was incubated on BHI for $24 \mathrm{~h}$ at $30{ }^{\circ} \mathrm{C}$ under agitation $(50 \mathrm{rpm})$. After 0 , 8 and $24 \mathrm{~h}$ of incubation, $0.1 \mathrm{~mL}$ each of this solution was taken and plated in BHI agar plates by using spread plate technique. Then, BHI plates were incubated at $30{ }^{\circ} \mathrm{C}$ for $24 \mathrm{~h}$ and the colonies were counted. The experiments were performed twice, and viable cell counts were expressed as $\log \mathrm{CFU} / \mathrm{mL}$.

\section{Statistical Analyses}

Statistical analyses were performed using the analysis of variance (ANOVA) procedure with SigmaPlot 11.0 software for Windows. Tukey's test was applied to detect differences of means, and $p<0.05$ was considered to be statistically significant.

\section{Results and Discussion}

Structural and Morphological Analyses

\section{X-Ray Diffraction Analysis}

Intercalation of $\mathrm{k}$-car/LBG chains between the clay platelets can be deduced by comparing the $d$-spacing values from the $\mathrm{XRD}$ analysis reflections of the layered pure $\mathrm{C} 30 \mathrm{~B}$ clays with those of the $d$-spacing values from the XRD reflections of the layered biocomposite films. The characteristic C30B diffraction peaks centred at $4.8^{\circ}$ and $19.8^{\circ}$ disappeared when 1 and 2 wt. $\%$ C30B was added to the $\mathrm{K}$-car/LBG film matrix. This means that $\mathrm{C} 30 \mathrm{~B}$ present in the film had a $d$-spacing higher than the $\mathrm{C} 30 \mathrm{~B}$ powder due to exfoliation of the clay platelets in the $\mathrm{K}$-car/LBG matrix (Ray and Bousmina 2005). This results are in agreement with those reported by Aouada et al. (2011). These authors showed that, at lower clay concentration (1 and 2 wt.\%), intercalation and complete exfoliation of the clay platelets happen in a thermoplastic starch matrix. The 4 wt. $\%$ C30B films showed a new diffraction peak at $2 \theta=4.0^{\circ}$ when comparing to neat $\mathrm{K}-\mathrm{car} / \mathrm{LBG}$ film. The diffraction peak observed for $4 \mathrm{wt} . \%$ films shifted to $4.1^{\circ}$ and $4.4^{\circ}$ when $\mathrm{C} 30 \mathrm{~B}$ concentrations increased to 8 and $16 \mathrm{wt} . \%$, respectively. The films containing 4,8 and $16 \mathrm{wt} . \%$ of $\mathrm{C} 30 \mathrm{~B}$ showed values of 21.9, 21.4 and $20.1 \AA$, respectively, of the $d$-spacing of platelets. This fact indicates that many of the fillers were probably present as intercalated platelets stacked in the $\mathrm{K}$-car/LBG film matrix instead of exfoliated (Ray and Bousmina 2005). These results are consistent with those reported for $\mathrm{C} 30 \mathrm{~B}-$ polysaccharide composite films (Rhim et al. 2006; Lim et al. 2010). Compatibility and optimum interactions between the polymer matrix, organic modifiers and the silicate layer surface itself are crucial to the formation of an intercalated or exfoliated composite. C30B could interact with K-car and LBG molecules to form hydrogen bonds, as shown by FTIR spectra (please see "FTIR"), between the carbonyl groups in polysaccharides and the hydroxyl groups in methyl tallow bis2-hydroxyethyl ammonium residing at the silicate layers of C30B. Thus, they form a clay-polymer network within the film matrix. Nugent et al. (2009) also reported that guar gum can form a linked clay-polymer network through hydrogen 
bonding between the biopolymer and clay particles. According to the high intensity of 8 and $16 \mathrm{wt} . \%$ clay biocomposite film diffraction peaks, the aggregation degree should be high. These diffraction peaks may be caused by the difficulty to break down higher C30B agglomerates of this sample, which could lead to the formation of some clay aggregates and consequently polysaccharide molecules experience more difficulty diffusing into the clay interlayers (Frounchi et al. 2006).

\section{Scanning Electron Microscopy}

SEM micrographs representative of films with different C30B concentrations are presented in Fig. 1 and were used to investigate fillers dispersion. The upper surface of $\mathrm{K}$-car/
LBG without C30B was very smooth (Fig. 1a). The film images corresponding to concentrations of 1 and $2 \mathrm{wt} . \%$ C30B showed a homogeneous dispersion of very small platelets of montmorillonite (Fig. 1b, c). On the other hand, the film surface of the films became rougher as the $\mathrm{C} 30 \mathrm{~B}$ concentration increased. Some aggregates of $\mathrm{C} 30 \mathrm{~B}$ were found at concentrations above 4 wt.\% (Fig. 1d-f). SEM pictures of $\mathrm{K}$-car/LBG composite films showed that films that are most highly loaded with $\mathrm{C} 30 \mathrm{~B}$ were not exfoliated. SEM images suggested that the $\mathrm{C} 30 \mathrm{~B}$ keeps intercalated and exfoliated structures at lower $\mathrm{C} 30 \mathrm{~B}$ concentration, while for higher $\mathrm{C} 30 \mathrm{~B}$ concentration, the $\mathrm{C} 30 \mathrm{~B}$ layers assemble to form intercalated and flocculated structures. $\mathrm{C} 30 \mathrm{~B}$ possessing methyl tallow bis-2-hydroxyethyl ammonium cations
Fig. 1 SEM photographs of the surface of $\mathrm{K}$-car/LBG films with a 0 wt. $\%$, b 1 wt. $\%$, c 2 wt. $\%$, d 4 wt. $\%$, e 8 wt. $\%$ and $\mathbf{f} 16$ wt. $\%$ C30B
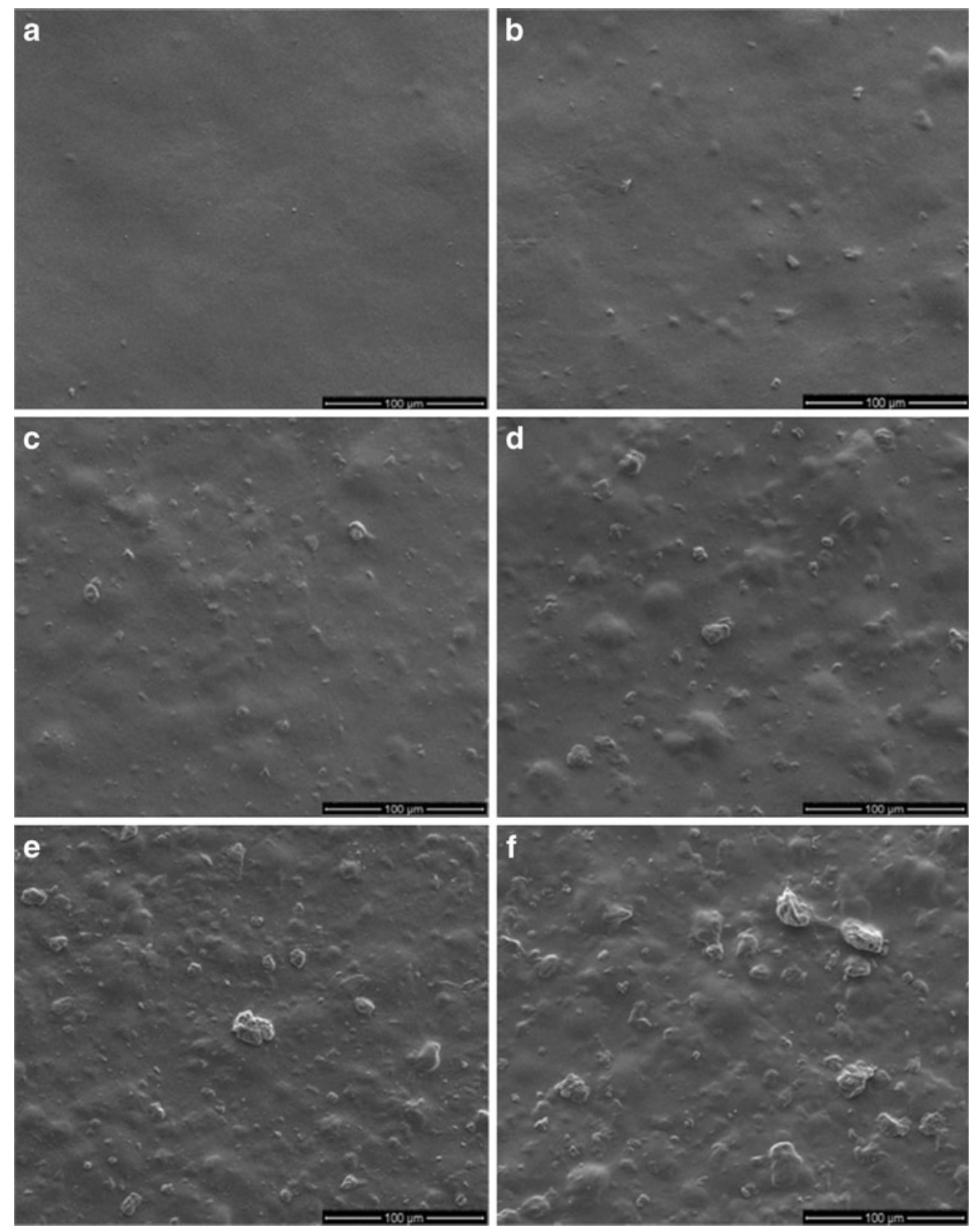
are less hydrophilic in comparison to the unmodified clay (Park et al. 2003), and for this reason, at high concentrations, $\mathrm{C} 30 \mathrm{~B}$ dispersed poorly, leading to the presence of large agglomerates when dispersed into the $\mathrm{k}$-car/LBG film matrix. These results were consistent with the results of the XRD having an exfoliated, intercalated or tactoid structure when the concentration of $\mathrm{C} 30 \mathrm{~B}$ is gradually increased in the $\mathrm{K}$-car/LBG film matrix.

\section{FTIR}

The chemical interactions between $\mathrm{k}$-car/LBG films and C30B were studied using FTIR spectroscopy (Fig. 2). The FTIR spectrum of $\mathrm{K}$-car/LBG-C30B showed the typical bands corresponding to the $\mathrm{K}-\mathrm{car} / \mathrm{LBG}$ (Fig. 2), corroborating the results previously reported by Martins et al. (2011). The main FTIR bands observed in the $\mathrm{K}$-car/LBG film spectra and their assignments are summarized in Table 1.

Various authors reported that $\mathrm{C} 30 \mathrm{~B}$ powder present characteristic bands at $3,630 \mathrm{~cm}^{-1}\left(\nu_{\mathrm{OH}}\right), 3,430 \mathrm{~cm}^{-1}\left(\nu_{\mathrm{OH}}\right.$ from interlayer water), $3,000-2,800 \mathrm{~cm}^{-1}\left(\nu_{\mathrm{C}-\mathrm{H}}\right.$ from $\mathrm{CH}_{2}$ and $\mathrm{CH}_{3}$ groups), $1,640 \mathrm{~cm}^{-1}$ ( $\delta_{\mathrm{OH}}$ from absorbed water) and $1,480-1,450 \mathrm{~cm}^{-1}\left(\delta_{\mathrm{C}-\mathrm{H}}\right.$ from $\mathrm{CH}_{2}$ bending $)$ and 800 $1,100 \mathrm{~cm}^{-1}\left(\nu_{\mathrm{Si}-\mathrm{O}}\right)$ (Barick and Tripathy 2010 ; Paluszkiewicz et al. 2011; Rodríguez et al. 2012). Once C30B and Kcar/LBG characteristic bands overlapped, the changes introduced by the addition of clay to film matrix were minor when observed by FTIR spectra. However, shifts in peak position of the participating groups and the occurrence of shifts and changes of area band between 950 and $1,200 \mathrm{~cm}^{-1}$ was detected. These differences may be caused by different types of clay-biopolymer interactions involved for the two biopolymers. In order to check this, the corresponding peaks and areas resulting from FTIR spectra deconvolution are presented in Table 2 . When clay concentration increases from 0 to $16 \mathrm{wt} . \%$, the absorption peaks at 997, 1,027 and $1,058 \mathrm{~cm}^{-1}$ shifted to $989,1,023$ and $1,056 \mathrm{~cm}^{-1}$, respectively. Also, the $\mathrm{k}-\mathrm{car} / \mathrm{LBG}$ absorption peaks at 1,114 and $1,149 \mathrm{~cm}^{-1}$ were found to be shifted to lower wavelengths when the clay concentration increased in the film (Table 2). As previously stated, these peaks are ascribed to $\nu_{\mathrm{C}-\mathrm{O}}$ of $\mathrm{C}-\mathrm{O}-\mathrm{C}$ and $\mathrm{C}-\mathrm{O}-\mathrm{H}$ groups of polysaccharides (Table 1) (Matsuhiro and Rivas 1993; GómezOrdóñez and Rupérez 2011). Moreover, the increase in area could be related with the intensity of interactions between the $\mathrm{k}-\mathrm{car} / \mathrm{LBG}$ and $\mathrm{C} 30 \mathrm{~B}$. The increase in the area of the peaks as well as the shifting of the $\mathrm{C}-\mathrm{O}$ peaks in $\mathrm{K}$-car/LBG confirms that the $\mathrm{OH}$ group of $\mathrm{K}$-car/LBG could take part in hydrogen bond formation. Liu et al. (2011) also reported the presence of shift at $999 \mathrm{~cm}^{-1}$ in starch biopolymer and clay due to newly formed hydrogen bonds.

On the basis of the shifting of characteristic $\mathrm{k}-\mathrm{car} / \mathrm{LBG}$ peaks, it can be inferred that intercalation of $\mathrm{K}$-car/LBG has taken place within clay layer as demonstrated by XRD analyses. Thus, hydrogen bonds or electrostatic interactions may have occurred between $\mathrm{C} 30 \mathrm{~B}$ and $\mathrm{K}$-car/LBG matrix. Since K-car/LBG possesses hydroxyl functional groups, these functional groups can form hydrogen bonds with the silicate hydroxylated edge groups, which lead to the interaction between matrix and silicate layers (Nugent et al. 2009).

Gases Permeability $-P_{\text {vapour }}, \mathrm{PO}_{2}, \mathrm{PCO}_{2}$

The $P_{\text {vapour }}, \mathrm{PO}_{2}$ and $\mathrm{PCO}_{2}$ values for the different clay loadings in $\mathrm{K}$-car/LBG blend are reported in Fig. 3. In general, $\mathrm{C} 30 \mathrm{~B}$ incorporation into the $\mathrm{k}-\mathrm{car} / \mathrm{LBG}$ matrix decreases the $P_{\text {vapour }}$ of the films. Results showed that clay addition into the $\mathrm{K}$-car/LBG matrix $(0 \mathrm{wt} . \% \mathrm{C} 30 \mathrm{~B})$ decreased the $P_{\text {vapour }}$ of the films by about $40 \%$ for $16 \mathrm{wt} . \%$ C30B. The $P_{\text {vapour }}$ of blend films changed significantly ( $p<$ 0.05 ) depending on the concentration of clays added to the film. This may have resulted from clay layer dispersion state in the film that could increase the tortuosity and block the micro-paths in the network microstructure, making the diffusion of water molecules through the matrix more difficult (Rhim 2011). Consequently, overall transport of water across the films was decreased. A similar behaviour was
Fig. 2 FTIR spectra of $\mathrm{k}$-car/ LBG film containing $0,1,2,4$, 8 and 16 wt. $\%$ C30B

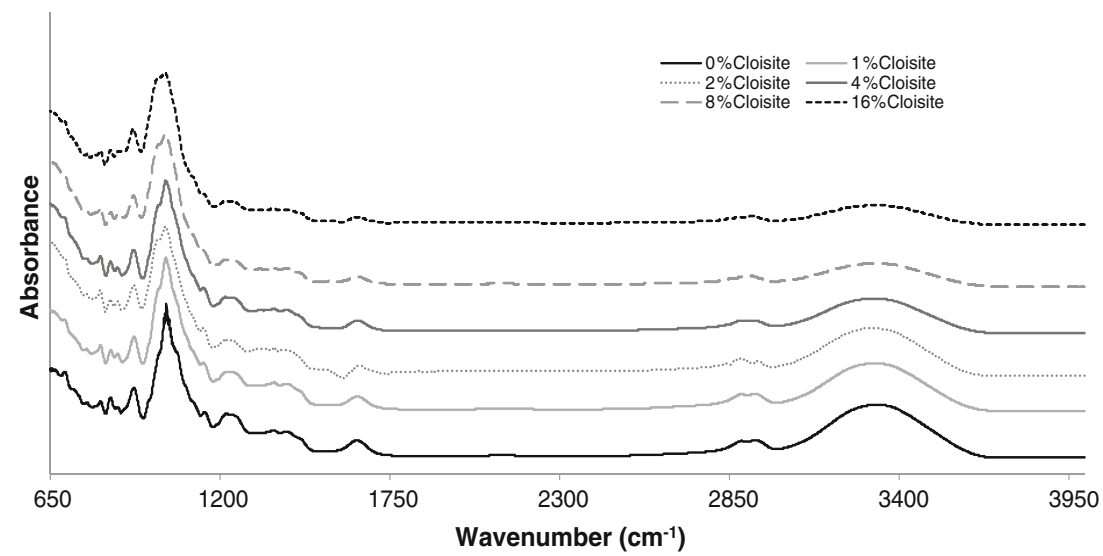


Table 1 Assignment of the main bands of the FTIR spectra for the K-car/LBG films

\begin{tabular}{llll}
\hline Band position $\left(\mathrm{cm}^{-1}\right)$ & BI & Assignment & References \\
\hline $700-950$ & - & Glucose ring stretching vibrations & Gómez-Ordóñez and Rupérez (2011) \\
$840-850$ & w & $\nu_{\mathrm{C}-\mathrm{O}-\mathrm{S}}($ galactose-4-sulfate $)$ & Prado-Fernández et al. (2003) \\
930 & w & $\nu_{\mathrm{C}-\mathrm{O}}(3,6$-anhydrogalactose $)$ & Nanaki et al. (2010) \\
$950-1,200$ & - & $\nu_{\mathrm{C}-\mathrm{O}-\mathrm{C}}, \nu_{\mathrm{C}-\mathrm{C}}, \delta_{\mathrm{C}-\mathrm{O}}$ & Liu et al. (2011) \\
$1,025-1,080$ & $\mathrm{~s}$ & $\nu_{\mathrm{C}-\mathrm{O}}(\mathrm{C}-\mathrm{OH}$ and $\mathrm{C}-\mathrm{O}-\mathrm{C}$ ring groups) & Paluszkiewicz et al. (2011) \\
$1,140-1,160$ & $\mathrm{w}$ & $\nu_{\mathrm{C}-\mathrm{O}-\mathrm{C}}(\mathrm{C}-\mathrm{O}-\mathrm{C}$ ring group) & Prado-Fernández et al. (2003) \\
1,230 & $\mathrm{w}$ & $\nu_{\mathrm{O}=\mathrm{S}=\mathrm{O}}$ & Gómez-Ordóñez and Rupérez (2011) \\
1,646 & $\mathrm{w}$ & $\nu_{\mathrm{C}=\mathrm{O}}$ & Kulkarni et al. (2011) \\
$2,850-2,950$ & $\mathrm{w}$ & $\nu_{\mathrm{C}-\mathrm{H}}\left(\mathrm{CH} \mathrm{H}_{2}\right.$ and $\mathrm{CH}_{3}$ groups) & Faria et al. (2011) \\
$3,000-3,750$ & $\mathrm{~m}$ & $\nu_{\mathrm{OH}}$ & Yuen et al. (2009) \\
\hline
\end{tabular}

$B I$ band intensity, $w$ weak, $m$ moderate, $s$ strong, $\nu$, stretching vibration, $\delta$ bending vibration

found in pectin/clay (Vartiainen et al. 2010) and chitosan/ clay (Lavorgna et al. 2010) composite films where the increasing clay concentration led to lower values of $P_{\text {vapour }}$.

$\mathrm{PO}_{2}$ values are reported in Fig. 3 for the different films. When comparing the $\mathrm{PO}_{2}$ of $\mathrm{K}$-car/LBG films with different clay concentrations, $\mathrm{k}-\mathrm{car} / \mathrm{LBG}$ films without $\mathrm{C} 30 \mathrm{~B}$ present higher values than films with clay $(p<0.05)$. However, there was no significant difference $(p>0.05)$ between 0 and 16 wt.\%. From the XRD pattern results, the levels of exfoliation with various clay concentrations indicate their dispersibility; therefore, it can be considered that $\mathrm{K}$-car/LBG composite matrix is exfoliated or intercalated in case of 1,2 , 4 and 8 wt.\% C30B. The large $d$-spacing value means that the gap between silicate layers is broad. Consequently, the composite membranes packed by $\mathrm{C} 30 \mathrm{~B}$ had the largest $d$ spacing value, resulting on high gas barrier properties due to possible increases in the tortuosity of the film structure. Vartiainen et al. (2010) reported an increase of oxygen barrier properties of clay-containing pectin films. The 1wt.\% C30B film showed a reduction in $\mathrm{PCO}_{2}(p<0.05)$ compared to the neat $\mathrm{K}$-car/LBG film from $2.26 \times 10^{-14}$ to $1.57 \times 10^{-14} \mathrm{~g}(\mathrm{~m} \mathrm{sPa})^{-1}$, respectively (Fig. 3). Further increase in clay loading from 1 to $8 \mathrm{wt} . \%$ did not significantly increase $(p>0.05)$ the $\mathrm{PCO}_{2}$ values compared to the neat $\mathrm{K}-$ car/LBG film. On the other hand, K-car/LBG-16 wt.\% C30B film presented the highest $(p<0.05) \mathrm{PCO}_{2}$ value $(2.91 \times$ $\left.\left.10^{-14} \mathrm{~g} \mathrm{(m} \mathrm{sPa}\right)^{-1}\right)$ (Fig. 3). Casariego et al. (2009) reported that clay addition to chitosan films had no influence in $\mathrm{PCO}_{2}$. However, the mechanism of interaction between $\mathrm{CO}_{2}$ and the films composed of $\mathrm{C} 30 \mathrm{~B}$ needs further investigation.

This difference between the effects of clay concentration on gas permeability is attributed to the shape and dispersion of the plate-like clays (Choudalakis and Gotsis 2009) which, in turn, depend on the compatibility between the biopolymers matrix and the surface functionalities of the C30B. While high concentrations of clay may form aggregates or clusters (Fig. 1), low concentrations may exfoliate into its individual layers that can, if properly oriented, impact the molecular transport of penetrant gases. Once there is little or no exfoliation of the clay platelets at higher $\mathrm{C} 30 \mathrm{~B}$ concentrations, as seen in XRD patterns, the barrier properties of clay fabric films most likely arise from the filling of voids between platelet edges instead of the tortuous path model (Triantafyllidis et al. 2006). In the present work, a decrease was observed in $\mathrm{PO}_{2}$ and $\mathrm{PCO}_{2}$ through $\mathrm{K}-\mathrm{car} / \mathrm{LBG}-\mathrm{C} 30 \mathrm{~B}$ film until a critical clay concentration was attained, after which an increase of permeability was detected. These results are in agreement with the ones observed by Alves et al. (2010) for K-car/pectin blends and mica flakes. These authors suggested a lack of clay exfoliation or decrease of aspect ratios (i.e. micrometer-sized particles instead of

Table 2 Centroids and fractional areas of bands between 950 and $1,200 \mathrm{~cm}^{-1}$ for $\mathrm{K}-\mathrm{car} / \mathrm{LBG}-\mathrm{C} 30 \mathrm{~B}$ composite films

\begin{tabular}{lcccccccccc}
\hline C30B (wt.\%) & Centroid & Area (\%) & Centroid & Area (\%) & Centroid & Area (\%) & Centroid & Area (\%) & Centroid & Area (\%) \\
\hline 0 & 997 & 18.39 & 1,027 & 33 & 1,058 & 21.27 & 1,114 & 6.61 & 1,149 & 4.24 \\
1 & 993 & 21.41 & 1,026 & 35.62 & 1,057 & 35.62 & 1,112 & 10.07 & 1,146 & 6.65 \\
2 & 990 & 26.29 & 1,025 & 35.83 & 1,059 & 22.05 & 1,097 & 10.64 & 1,143 & 5.18 \\
4 & 993 & 24.16 & 1,027 & 37.67 & 1,062 & 22.52 & 1,100 & 10.49 & 1,143 & 5.14 \\
8 & 990 & 28.71 & 1,025 & 38.96 & 1,058 & 23.08 & 1,101 & 8.31 & 1,143 & 2.95 \\
16 & 989 & 31.24 & 1,023 & 36.97 & 1,056 & 23.41 & 1,103 & 6.92 & 1,146 & 1.45 \\
\hline
\end{tabular}




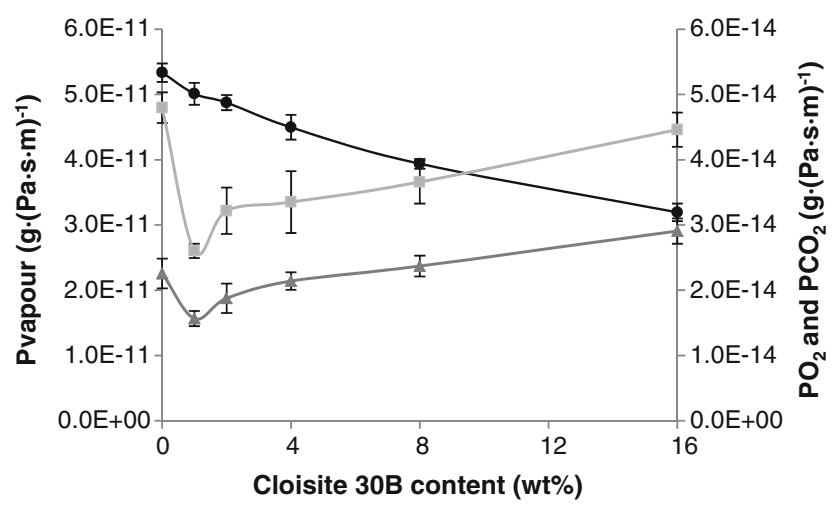

Fig. 3 Water vapour $\left(P_{\text {vapour }}\right)$ (filled circle), oxygen $\left(\mathrm{PO}_{2}\right)$ (filled square) and carbon dioxide $\left(\mathrm{PCO}_{2}\right)$ (filled triangle) permeabilities of $\mathrm{K}$-car/LBG composite films with increasing Cloisite 30B concentrations. The error bars indicate the standard deviations

nanometer-sized particles) as a possible explanation for this phenomenon. As a consequence of the permeability studies, the barrier properties of $\mathrm{K}$-car/LBG film for use in food packaging, protective coating and other applications can be improved with the addition of $\mathrm{C} 30 \mathrm{~B}$ to the polymer matrix. The inclusion of $16 \mathrm{wt} . \% \mathrm{C} 30 \mathrm{~B}$ on $\mathrm{k}$-car/LBG film samples represents the level of clay addition that allows a lower $P_{\text {vapour }}$ compared to other film samples. In what concerns $\mathrm{PO}_{2}$ and $\mathrm{PCO}_{2}, 1-\mathrm{wt} . \% \mathrm{C} 30 \mathrm{~B}$ films showed higher reduction of gas permeability.

\section{Mechanical Properties}

In general, the biocomposite films showed higher TS and EB values when clay concentration increased, as can be observed from Table 3. Although the increasing amount of C30B led to the presence of some particulates (shown in the SEM micrographs; Fig. 1) caused by the agglomeration of fillers, the mechanical properties were apparently not affected by exfoliation degree of the clay in film. Kumar et al. (2010a) reported a similar effect of $\mathrm{C} 30 \mathrm{~B}$ concentration on tensile properties when they prepared films based on soy protein isolate/clay composites by melt extrusion. TS values

Table 3 Values of thickness, tensile strength and elongation-at-break of $\mathrm{k}-\mathrm{car} / \mathrm{LBG}-30 \mathrm{~B}$ composite films

\begin{tabular}{llll}
\hline C30B (wt.\%) & Thickness (mm) & TS (MPa) & EB (\%) \\
\hline 0 & $0.043 \pm 0.001 \mathrm{a}$ & $26.88 \pm 0.56 \mathrm{a}$ & $18.88 \pm 0.90 \mathrm{a}$ \\
1 & $0.051 \pm 0.002 \mathrm{ab}$ & $28.73 \pm 0.37 \mathrm{~b}$ & $22.64 \pm 1.06 \mathrm{~b}$ \\
2 & $0.054 \pm 0.004 \mathrm{ab}$ & $29.27 \pm 0.42 \mathrm{~b}$ & $25.06 \pm 0.75 \mathrm{c}$ \\
4 & $0.057 \pm 0.003 \mathrm{bc}$ & $28.38 \pm 0.67 \mathrm{~b}$ & $26.23 \pm 0.78 \mathrm{~d}$ \\
8 & $0.060 \pm 0.002 \mathrm{c}$ & $29.79 \pm 1.74 \mathrm{~b}$ & $26.82 \pm 0.75 \mathrm{~d}$ \\
16 & $0.062 \pm 0.003 \mathrm{c}$ & $33.82 \pm 0.51 \mathrm{c}$ & $29.82 \pm 1.01 \mathrm{e}$
\end{tabular}

Means followed by the same letter in the same column are not significantly different at $p<0.05$ according to Tukey's test obtained for K-car/LBG-clay films (Table 3) are in the same range of agar/clay composite films-28-36 MPa (Rhim 2011). The methyl tallow bis-2-hydroxy ethyl quaternary ammonium in $\mathrm{C} 30 \mathrm{~B}$ has two $-\mathrm{OH}$ groups in its structure, which might act as the "bridge" connecting the polymer chains and clay layers (Nayak and Mohanty 2010). This phenomenon may contribute to an increase of TS values. Lee and Kim (2010) also explained that the improved TS of soy protein isolate/montmorillonite composite films can be attributed to the interactions between the soy protein isolate matrix and layered silicates via the formation of hydrogen or ionic bonds.

$\mathrm{EB}$ values also increased for higher $\mathrm{C} 30 \mathrm{~B}$ concentrations in the film. This may be attributed to the interfacial affinity and interaction between film matrix and $\mathrm{C} 30 \mathrm{~B}$ modifier chains present on clay surfaces, which results in the formation of physically cross-linked networks and consequently increased EB in the film (Mirzataheri et al. 2010). The EB values are in the range of those reported by Lim et al. (2010) (15.0 to $33.21 \%$ ) for agarose films containing C30B. Thus, it can be concluded from the earlier observations that in a certain clay concentration range, the introduction of clay will lead to both a strengthening and a toughening of the K-car/LBG films. Moreover, TS values of K-car/LBG containing $\mathrm{C} 30 \mathrm{~B}$ are comparable to that of HDPE films (27.8 MPa), as reported by García et al. (2009). The EB values obtained for $\mathrm{K}$-car/LBG-C30B films were in the range of cellophane films (EB, 16-60\%) (Phan The et al. 2009). However, the EB values for $\mathrm{K}-\mathrm{car} / \mathrm{LBG}-\mathrm{C} 30 \mathrm{~B}$ films were considerably lower than LDPE $(68.7 \%)$ or HDPE $(150.0 \%)$ commercial synthetic polymer films (García et al. 2009).

\section{Thermogravimetric Analysis}

TGA was performed to determine the thermal stability of $\mathrm{K}$ car/LBG and $\mathrm{K}-\mathrm{car} / \mathrm{LBG}-\mathrm{C} 30 \mathrm{~B}$ films. Table 4 shows the peaks of the derivate of the weight loss curve (DrTG) where five weight losses were observed (temperatures ranged between 20 and $600{ }^{\circ} \mathrm{C}$ ). The first mass reduction happens at $60-70{ }^{\circ} \mathrm{C}$ and it is related to the adsorbed water molecules' vaporization (Lavorgna et al. 2010). The second weight loss at $206.5^{\circ} \mathrm{C}$ until the initial decomposition temperature corresponds to glycerol (plasticizer) evaporation (Aouada et al. 2011). The third weight loss at around $262.6{ }^{\circ} \mathrm{C}$ is possibly due to the thermal decomposition of the polysaccharides ( $\mathrm{K}$ carrageenan and galactomannan) (Abad et al. 2003; Das et al. 2011). The last two weight losses occurred between 450 and $560{ }^{\circ} \mathrm{C}$ and are related to the decomposition zone of subproducts formed during material degradation (Rodríguez et al. 2012). The peaks at $530-560{ }^{\circ} \mathrm{C}$ are also associated with the structural dehydroxylation of the residual structural $\mathrm{AlOH}$ groups (Hashemifard et al. 2011). 
Table 4 Weight loss (WL) and derivate of the weight loss curve (DrTG) for K-car/LBG-C30B films

\begin{tabular}{|c|c|c|c|c|c|c|c|c|c|c|}
\hline \multirow{2}{*}{$\begin{array}{l}\text { C30B } \\
\text { (wt.\%) }\end{array}$} & \multicolumn{2}{|l|}{ Peak 1} & \multicolumn{2}{|l|}{ Peak 2} & \multicolumn{2}{|l|}{ Peak 3} & \multicolumn{2}{|l|}{ Peak 4} & \multicolumn{2}{|l|}{ Peak 5} \\
\hline & $\operatorname{DrTG}\left({ }^{\circ} \mathrm{C}\right)$ & WL (\%) & $\operatorname{DrTG}\left({ }^{\circ} \mathrm{C}\right)$ & WL (\%) & $\operatorname{DrTG}\left({ }^{\circ} \mathrm{C}\right)$ & WL (\%) & $\operatorname{DrTG}\left({ }^{\circ} \mathrm{C}\right)$ & WL (\%) & $\operatorname{DrTG}\left({ }^{\circ} \mathrm{C}\right)$ & WL (\%) \\
\hline 0 & $70.8 \pm 8.3$ & $7.1 \pm 4.9$ & $206.5 \pm 3.0$ & $22.0 \pm 1.3$ & $262.6 \pm 0.9$ & $28.6 \pm 2.9$ & $365.3 \pm 6.3$ & $9.8 \pm 0.5$ & $513.3 \pm 7.7$ & $11.9 \pm 3.7$ \\
\hline 1 & $63.5 \pm 2.1$ & $9.9 \pm 0.5$ & $204.0 \pm 1.5$ & $19.1 \pm 3.5$ & $271.3 \pm 5.2$ & $29.0 \pm 5.1$ & $365.2 \pm 3.1$ & $8.8 \pm 0.6$ & $509.5 \pm 1.0$ & $15.6 \pm 1.2$ \\
\hline 2 & $60.8 \pm 3.3$ & $8.0 \pm 0.5$ & $205.1 \pm 1.0$ & $23.5 \pm 0.5$ & $263.0 \pm 0.4$ & $22.7 \pm 1.2$ & $357.6 \pm 8.3$ & $9.8 \pm 2.9$ & $537.2 \pm 7.4$ & $21.3 \pm 0.6$ \\
\hline 4 & $60.2 \pm 0.3$ & $11.0 \pm 2.6$ & $205.3 \pm 1.9$ & $20.1 \pm 0.1$ & $261.3 \pm 1.5$ & $22.9 \pm 0.7$ & $358.6 \pm 2.1$ & $10.7 \pm 0.4$ & $539.3 \pm 2.2$ & $20.0 \pm 0.9$ \\
\hline 8 & $60.5 \pm 2.9$ & $11.4 \pm 0.1$ & $208.3 \pm 1.3$ & $17.4 \pm 0.4$ & $262.1 \pm 2.4$ & $23.8 \pm 0.0$ & $369.4 \pm 14.2$ & $10.3 \pm 0.4$ & $554.7 \pm 0.5$ & $18.6 \pm 1.3$ \\
\hline 16 & $69.1 \pm 5.0$ & $8.2 \pm 0.2$ & $211.9 \pm 5.7$ & $14.6 \pm 1.6$ & $264.9 \pm 0.2$ & $25.8 \pm 0.2$ & $347.0 \pm 0.2$ & $7.1 \pm 1.2$ & $556.4 \pm 4.3$ & $14.3 \pm 4.8$ \\
\hline
\end{tabular}

The temperature of thermal degradation of $\mathrm{k}$-car/LBG films appeared to increase from 513 to 537 and to $556{ }^{\circ} \mathrm{C}$ when clay concentration increased to 2 and $16 \mathrm{wt} . \%$, respectively (Table 4). On the other hand, it remains unaffected and stable throughout the other thermal stages independent of clay concentration, as described by other authors (Casariego et al. 2009). Aouada et al. (2011) reported that exfoliated clays' structure could prevent water/plasticizer migration and evaporation. As $\mathrm{C} 30 \mathrm{~B}$ concentration increased, the biocomposite films showed a significant delay in weight loss at temperatures greater than $400{ }^{\circ} \mathrm{C}$. This can be due to the reduction of diffusion rate of volatile decomposition products out of the biocomposite bulk caused by the thermal insulation behaviour of clay platelets (Kumar et al. 2010b).

\section{Antimicrobial Activity}

The disc diffusion assay results showed that no loss of viability was found when $L$. monocytogenes, E. coli and $S$. enterica were in contact with the films without C30B. When clay was added to $\mathrm{K}$-car/LBG films, no inhibition halo and microbial growth were observed under the film for $E$. coli and S. enterica cells. In contrast, $\mathrm{K}-\mathrm{car} / \mathrm{LBG}-\mathrm{C} 30 \mathrm{~B}$ films had a bactericidal effect on the growth of $L$. monocytogenes once the halo zone clearly appeared. Inhibition zones of 8.17, 8.83, 9.67, 11.33 and $13.00 \mathrm{~mm}$ were observed against L. monocytogenes for 1, 2, 4, 8 and $16 \mathrm{wt} . \% \mathrm{~K}$-car/LBG-C30B films, respectively. It seems that $\mathrm{C} 30 \mathrm{~B}$ diffuses to the surrounding area of the film inhibiting the growth of L. monocytogenes. These findings are supported by the results of Nigmatullin et al. (2008); these authors reported that the antimicrobial activity of $\mathrm{C} 30 \mathrm{~B} /$ polymer composites is partially due to the ammonium salts released from the surfactant-modified clays. Moreover, the different behaviour observed between L. monocytogenes (Gram-positive) and E. coli and S. enterica (Gram-negative bacteria) could be explained by the differences in their cell wall structure. Gram-positive bacteria lack an outer membrane, allowing antimicrobial compounds to come into contact with sensitive bacterial targets located in the inner membrane, but Gram-negative bacteria are mainly protected from damage by their outer membrane (Malachová et al. 2009). The C30B cationic charge of the quaternary ammonium group and its hydrophobic alkyl chains could be main factors for the antimicrobial activity of the K-car/LBG-C30B films against Grampositive bacteria (Wang et al. 2008). This hypothesis was advanced once a similar behaviour has been previously reported by other authors for L. monocytogenes (Rhim et al. 2011; Sothornvit et al. 2010), Staphylococcus aureus (Rhim et
Fig. 4 Antimicrobial activity of $\mathrm{K}$-car/LBG film containing 0 , $1,2,4,8$ and 16 wt. $\%$ C30B against $L$. monocytogenes at different contact times $(0,8$ and $24 \mathrm{~h}$ ). The error bars indicate the standard deviations

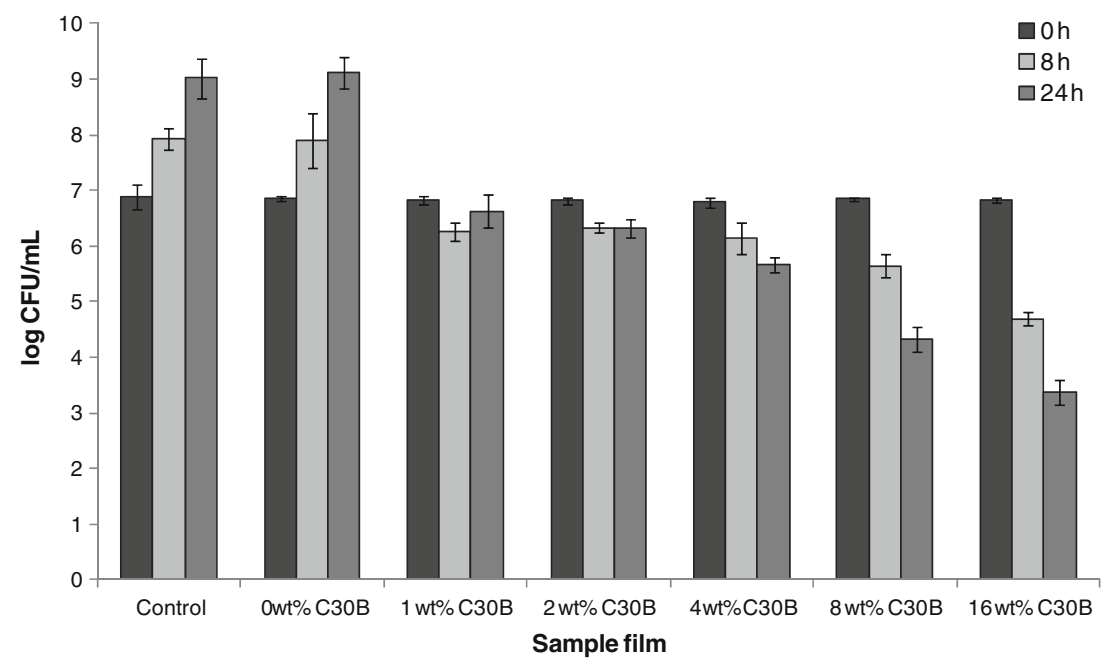


al. 2006) and Bacillus subtilis (Wang et al. 2006). It is clear from the results that the antimicrobial activity increases with increasing amounts of $\mathrm{C} 30 \mathrm{~B}$ in the film formulation. Even at lower clay concentrations (1 and 2 wt.\%), $\mathrm{k}-\mathrm{car} / \mathrm{LBG}-\mathrm{C} 30 \mathrm{~B}$ presented antimicrobial activity. This is in accordance with a previous work (Wang et al. 2006). These authors reported that the higher concentration or the interlayer distance of clay resulted in a stronger inhibitory activity against bacteria.

The results from the viable cell counts (Fig. 4) demonstrated that the antimicrobial action of the biocomposite film was attributable to $\mathrm{C} 30 \mathrm{~B}$ instead of the biopolymer matrix once no inhibitory effect was observed in film samples without C30B. The control (without $\mathrm{k}$-car/LBG film) and K-car/LBG film without $\mathrm{C} 30 \mathrm{~B}$ showed an increase of Listeria population by two $\log$ within $24 \mathrm{~h}$. The 1- and 2-wt.\% C30B-incorporated films demonstrated a bacteriostatic effect. Sothornvit et al. (2010) also reported that the incorporation of C30B (5-20 wt.\%) into whey protein isolate films showed a bacteriostatic effect against $L$. monocytogenes. Moreover, the increase of $\mathrm{C} 30 \mathrm{~B}$ concentration enhanced the film antimicrobial activity against $L$. monocytogenes. The films with C30B concentration above 4 wt.\% exhibited bactericidal effects. Also, films with 16 wt.\% exhibited the highest antimicrobial effect, reducing the initial bacteria population from $6.8 \log \mathrm{CFU} / \mathrm{mL}$ to 4.7 and $3.4 \log \mathrm{CFU} / \mathrm{mL}$ after 8 and $24 \mathrm{~h}$ of cultivation, respectively. Two possible mechanisms could explain the antimicrobial action of $\mathrm{K}-\mathrm{car} / \mathrm{LBG}-$ C30B films against $L$. monocytogenes. In the first mechanism, C30B addition to the $\mathrm{K}$-car/LBG films could directly affect bacteria cells' adhesion to the film through surface interactions (e.g. electrostatic and hydrophobic/hydrophilic interactions) (Wang et al. 2009). Subsequently, C30B could damage the cytoplasmic membrane of the bacterial cell and the normal physiology activity of the cell was completely altered, leading to the death of the cell. In the second mechanism, clay minerals can affect bacterial metabolism indirectly by altering the physicochemical properties of the environment, for example, by varying redox environment (Haydel et al. 2007).

These results showed that the incorporation of clay into the $\mathrm{K}$-car/LBG films could have advantages over films without clays and that $\mathrm{K}$-car/LBG-C30B biocomposite films have the potential to be used as antimicrobial packaging to control the growth of L. monocytogenes.

\section{Conclusion}

This study demonstrated that the physicochemical properties of K-car/LBG films were influenced by clay concentration. The XRD and SEM results showed that at low filler concentration, exfoliation is the predominant mechanism of clay dispersion. However, increase of clay loading impedes complete exfoliation due to the restricted area remaining available in the polymer matrix and increases the degree of intercalation or aggregation of clays. Additionally, FTIR results demonstrated a possible formation of hydrogen bond interactions between k-car/LBG matrix and C30B. Meanwhile, mechanical properties showed the potential of films based on $\mathrm{K}$-car/LBG and $\mathrm{C} 30 \mathrm{~B}$ to be used in food packaging (with values in the range of synthetic films). The differences in the gas permeability values may be due to the different structure of the composites (being of the intercalation or exfoliation type). At temperatures greater than $500{ }^{\circ} \mathrm{C}$, TGA results showed that $\mathrm{C} 30 \mathrm{~B}$ significantly delays the thermal degradation of $\mathrm{K}$-car/LBG films. Moreover, the antimicrobial activity results demonstrated that $\mathrm{C} 30 \mathrm{~B}$ incorporation into biopolymer matrix as a filler to improve film properties can also act as an antimicrobial agent against $L$. monocytogenes. Therefore, it was observed that the composition of $16 \mathrm{wt} . \% \mathrm{C} 30 \mathrm{~B}$ in the $\mathrm{K}$-car/LBG film represents a good option to be used in food packaging industry due to their good mechanical properties, enhanced water barrier and antibacterial activity when compared with other $\mathrm{C} 30 \mathrm{~B}$ concentrations tested.

Acknowledgments J. T. Martins, A. I. Bourbon, A. C. Pinheiro and M. A. Cerqueira gratefully acknowledge the Fundação para a Ciência e Tecnologia (FCT, Portugal) for their fellowships (SFRH/BD/32566/ 2006, SFRH/BD/73178/2010, SFRH/BD/48120/2008 and SFRH/ BPD/72753/2010, respectively), and B. W. S. Souza acknowledges the Coordenação de Aperfeiçoamento de Pessoal de Nível Superior (CAPES, Brazil).

\section{References}

Abad, L. V., Relleve, L. S., Aranilla, C. T., \& Dela Rosa, A. M. (2003). Properties of radiation synthesized PVP-kappa carrageenan hydrogel blends. Radiation Physics and Chemistry, 68(5), 901908.

Alves, V. D., Costa, N., \& Coelhoso, I. M. (2010). Barrier properties of biodegradable composite films based on kappa-carrageenan/pectin blends and mica flakes. Carbohydrate Polymers, 79(2), 269276.

Aouada, F. A., Mattoso, L. H. C., \& Longo, E. (2011). New strategies in the preparation of exfoliated thermoplastic starch-montmorillonite nanocomposites. Industrial Crops and Products, 34, 15021508 .

Arda, E., Kara, S., \& Pekcan, Ö. (2009). Synergistic effect of the locust bean gum on the thermal phase transitions of K-carrageenan gels. Food Hydrocolloids, 23(2), 451-459.

Barick, A. K., \& Tripathy, D. K. (2010). Preparation and characterization of thermoplastic polyurethane/organoclay nanocomposites by melt intercalation technique: effect of nanoclay on morphology, mechanical, thermal, and rheological properties. Journal of Applied Polymer Science, 117(2), 639-654.

Casariego, A., Souza, B. W. S., Cerqueira, M. A., Teixeira, J. A., Cruz, L., Díaz, R., \& Vicente, A. A. (2009). Chitosan/clay films' properties as affected by biopolymer and clay micro/nanoparticles' concentrations. Food Hydrocolloids, 23(7), 1895-1902.

Cerqueira, M. A., Souza, B. W. S., Teixeira, J. A., \& Vicente, A. A. (2011). Effects of interactions between the constituents of 
chitosan-edible films on their physical properties. Food and Bioprocess Technology. doi:10.1007/s11947-011-0663-y.

Choudalakis, G., \& Gotsis, A. D. (2009). Permeability of polymer/clay nanocomposites: a review. European Polymer Journal, 45(4), 967-984.

Das, D., Ara, T., Dutta, S., \& Mukherjee, A. (2011). New water resistant biomaterial biocide film based on guar gum. Bioresource Technology, 102(10), 5878-5883.

Faria, S., de Oliveira Petkowicz, C. L., de Morais, S. A. L., Terrones, M. G. H., de Resende, M. M., de França, F. P., \& Cardoso, V. L. (2011). Characterization of xanthan gum produced from sugar cane broth. Carbohydrate Polymers, 86(2), 469-476.

Frounchi, M., Dadbin, S., Salehpour, Z., \& Noferesti, M. (2006). Gas barrier properties of PP/EPDM blend nanocomposites. Journal of Membrane Science, 282(1-2), 142-148.

García, M. A., Pinotti, A., Martino, M. N., \& Zaritzky, N. E. (2009). Characterization of starch and composite edible films and coatings. In M. E. Embuscado \& K. C. Huber (Eds.), Edible films and coatings for food applications (pp. 169-209). New York: Springer.

Gómez-Ordóñez, E., \& Rupérez, P. (2011). FTIR-ATR spectroscopy as a tool for polysaccharide identification in edible brown and red seaweeds. Food Hydrocolloids, 25(6), 1514-1520.

Hashemifard, S. A., Ismail, A. F., \& Matsuura, T. (2011). Effects of montmorillonite nano-clay fillers on PEI mixed matrix membrane for $\mathrm{CO}_{2}$ removal. Chemical Engineering Journal, 170(1), 316325 .

Haydel, S. E., Remenih, C. M., \& Williams, L. B. (2007). Broadspectrum in vitro antibacterial activities of clay minerals against antibiotic-susceptible and antibiotic-resistant bacterial pathogens. Journal of Antimicrobial Chemotherapy, 61(2), 353-361.

Kulkarni, R. V., Baraskar, V. V., Setty, C. M., \& Sa, B. (2011). Interpenetrating polymer network matrices of sodium alginate and carrageenan for controlled drug delivery application. Fibers and Polymers, 12(3), 352-358.

Kumar, P., Sandeep, K. P., Alavi, S., Truong, V. D., \& Gorga, R. E. (2010a). Effect of type and content of modified montmorillonite on the structure and properties of bio-nanocomposite films based on soy protein isolate and montmorillonite. Journal of Food Science, 75(5), N46-N56.

Kumar, P., Sandeep, K. P., Alavi, S., Truong, V. D., \& Gorga, R. E. (2010b). Preparation and characterization of bio-nanocomposite films based on soy protein isolate and montmorillonite using melt extrusion. Journal of Food Engineering, 100(3), 480-489.

Lavorgna, M., Piscitelli, F., Mangiacapra, P., \& Buonocore, G. G. (2010). Study of the combined effect of both clay and glycerol plasticizer on the properties of chitosan films. Carbohydrate Polymers, 82(2), 291-298.

Lee, J. E., \& Kim, K. M. (2010). Characteristics of soy protein isolatemontmorillonite composite films. Journal of Applied Polymer Science, 118(4), 2257-2263.

Lim, G.-O., Jang, S.-A., \& Song, K. B. (2010). Physical and antimicrobial properties of Gelidium corneum/nano-clay composite film containing grapefruit seed extract or thymol. Journal of Food Engineering, 98(4), 415-420.

Liu, H., Chaudhary, D., Yusa, S.-I., \& Tadé, M. O. (2011). Preparation and characterization of sorbitol modified nanoclay with high amylose bionanocomposites. Carbohydrate Polymers, 85(1), 97-104.

Malachová, K., Praus, P., Pavlíčková, Z., \& Turicová, M. (2009). Activity of antibacterial compounds immobilised on montmorillonite. Applied Clay Science, 43(3-4), 364-368.

Martins, J. T., Cerqueira, M. A., Bourbon, A. I., Pinheiro, A. C., \& Vicente, A. A. (2011). Edible films-based on k-carrageenan/locust bean gum - effects of different polysaccharide ratios on film properties. In: Proceedings of the 11th International Congress on
Engineering and Food. Food Process Engineering in a Changing World, 22-26 May 2011, Athens.

Matsuhiro, B., \& Rivas, P. (1993). Second-derivative Fourier transform infrared spectra of seaweed galactans. Journal of Applied Phycology, $5(1), 45-51$.

Mirzataheri, M., Atai, M., \& Mahdavian, A. R. (2010). Physical and mechanical properties of nanocomposite barrier film containing encapsulated nanoclay. Journal of Applied Polymer Science, 118 (6), 3284-3291.

Nanaki, S., Evangelos, K., Kalantzi, L., \& Bikiaris, D. (2010). Miscibility study of carrageenan blends and evaluation of their effectiveness as sustained release carriers. Carbohydrate Polymers, 79, $1157-1167$.

Nayak, S. K., \& Mohanty, S. (2010). Poly (trimethylene) terephthalate/ m-LLDPE blend nanocomposites: evaluation of mechanical, thermal and morphological behavior. Materials Science and Engineering $A$, 527(3), 574-583.

Nigmatullin, R., Gao, F., \& Konovalova, V. (2008). Polymer-layered silicate nanocomposites in the design of antimicrobial materials. Journal of Materials Science, 43(17), 5728-5733.

Nugent, R. A., Zhang, G., \& Gambrell, R. P. (2009). Effect of exopolymers on the liquid limit of clays and its engineering implications. Transportation Research Board: Journal of the Transportation Research Board, 2101, 34-43.

Paluszkiewicz, C., Stodolak, E., Hasik, M., \& Blazewicz, M. (2011). FT-IR study of montmorillonite-chitosan nanocomposite materials. Spectrochimica Acta Part A: Molecular and Biomolecular Spectroscopy, 79(4), 784-788.

Park, H.-M., Lee, W.-K., Park, C.-Y., Cho, W.-J., \& Ha, C.-S. (2003). Environmentally friendly polymer hybrids. Part I. Mechanical, thermal, and barrier properties of thermoplastic starch/clay nanocomposites. Journal of Materials Science, 38(5), 909-915.

Phan The, D., Debeaufort, F., Voilley, A., \& Luu, D. (2009). Biopolymer interactions affect the functional properties of edible films based on agar, cassava starch and arabinoxylan blends. Journal of Food Engineering, 90, 548-558.

Prado-Fernández, J., Rodríguez-Vázquez, J. A., Tojo, E., \& Andrade, J. M. (2003). Quantitation of K-, l- and $\lambda$-carrageenans by midinfrared spectroscopy and PLS regression. Analytica Chimica Acta, 480, 23-37.

Pranoto, Y., Salokhe, V. M., \& Rakshit, S. K. (2005). Physical and antibacterial properties of alginate-based edible film incorporated with garlic oil. Food Research International, 38(3), 267-272.

Ray, S., \& Bousmina, M. (2005). Biodegradable polymers and their layered silicate nanocomposites. In: Greening the 21st century materials world. Progress in Materials Science, 50(8), 962-1079.

Rhim, J.-W. (2011). Effect of clay contents on mechanical and water vapor barrier properties of agar-based nanocomposite films. Carbohydrate Polymers, 86(2), 691-699.

Rhim, J.-W., Hong, S.-I., Park, H.-M., \& Ng, P. K. W. (2006). Preparation and characterization of chitosan-based nanocomposite films with antimicrobial activity. Journal of Agricultural and Food Chemistry, 54(16), 5814-5822.

Rhim, J., Hong, S., \& Ha, C. (2009). Tensile, water vapor barrier and antimicrobial properties of PLA/nanoclay composite films. LWTFood Science and Technology, 42(2), 612-617.

Rhim, J.-W., Lee, S.-B., \& Hong, S.-I. (2011). Preparation and characterization of agar/clay nanocomposite films: the effect of clay type. Journal of Food Science, 76(3), N40-N48.

Rodríguez, F. J., Galotto, M. J., Guarda, A., \& Bruna, J. E. (2012). Modification of cellulose acetate films using nanofillers based on organoclays. Journal of Food Engineering, 110(2), 262-268.

Ruiz-Hitzky, E., Darder, M., \& Aranda, P. (2008). An introduction to bio-nanohybrid materials. In E. Ruiz-Hitzky, K. Ariga, \& Y. Lvov (Eds.), Bio-inorganic hybrid nanomaterials (pp. 1-40). Weinheim: Wiley. 
Ruiz-Hitzky, E., Aranda, P., Darder, M., \& Rytwo, G. (2010). Hybrid materials based on clays for environmental and biomedical applications. Journal of Materials Chemistry, 20(42), 9306-9321.

Sanchez-Garcia, M. D., Hilliou, L., \& Lagaron, J. M. (2010). Nanobiocomposites of carrageenan, zein, and mica of interest in food packaging and coating applications. Journal of Agricultural and Food Chemistry, 58(11), 6884-6894.

Sorrentino, A., Gorrasi, G., \& Vittoria, V. (2007). Potential perspectives of bio-nanocomposites for food packaging applications. Trends in Food Science \& Technology, 18(2), 84-95.

Sothornvit, R., Hong, S.-I., An, D. J., \& Rhim, J.-W. (2010). Effect of clay content on the physical and antimicrobial properties of whey protein isolate/organo-clay composite films. LWT-Food Science and Technology, 43(2), 279-284.

Triantafyllidis, K. S., LeBaron, P. C., Park, I., \& Pinnavaia, T. J. (2006). Epoxy-clay fabric film composites with unprecedented oxygenbarrier properties. Chemistry of Materials, 18(18), 4393-4398.

Vartiainen, J., Tammelin, T., Pere, J., Tapper, U., \& Harlin, A. (2010). Biohybrid barrier films from fluidized pectin and nanoclay. Carbohydrate Polymers, 82(3), 989-996.
Voon, H. C., Bhat, R., Easa, A. M., Liong, M. T., \& Karim, A. A. (2010). Effect of addition of halloysite nanoclay and $\mathrm{SiO}_{2}$ nanoparticles on barrier and mechanical properties of bovine gelatin films. Food and Bioprocess Technology. doi:10.1007/s11947010-0461-y.

Wang, X., Du, Y., Yang, J., Wang, X., Shi, X., \& Hu, Y. (2006). Preparation, characterization and antimicrobial activity of chitosan/layered silicate nanocomposites. Polymer, 47(19), 67386744.

Wang, X., Du, Y., Yang, J., Tang, Y., \& Luo, J. (2008). Preparation, characterization, and antimicrobial activity of quaternized chitosan/ organic montmorillonite nanocomposites. Journal of Biomedical Materials Research. Part A, 84A(2), 384-390.

Wang, X., Du, Y., Luo, J., Yang, J., Wang, W., \& Kennedy, J. F. (2009). A novel biopolymer/rectorite nanocomposite with antimicrobial activity. Carbohydrate Polymers, 77(3), 449-456.

Yuen, S.-N., Choi, S.-M., Phillips, D. L., \& Ma, C.-Y. (2009). Raman and FTIR spectroscopic study of carboxymethylated non-starch polysaccharides. Food Chemistry, 114(3), 10911098. 